\title{
TRANSFORMATION OF THE INSTITUTE OF THE SOURCE OF INCREASED DANGER IN THE INFORMATION AND DIGITAL ERA
}

\author{
Sophia R. Deryugina
}

Volgograd State University, Volgograd, Russian Federation

\begin{abstract}
Introduction: the development of the latest information and telecommunication technologies used in the civil law sphere transforms the understanding and application of tort liability for damage caused by a source of increased danger. The identified mechanism requires a scientific analysis to determine the essential changes in the institution of a source of increased danger. The implementation of activities related to the sources of increased danger implies the presence of a threat of harm to the subjects of law. To ensure the greatest protection of subjects, digital technologies are used. The purpose of the study: to determine the characteristics of the concept "owner of a source of increased danger", to consider the impact of digital technologies on the institution of a source of increased danger. Methods: general method; general scientific method (logical (induction, deduction, analysis, synthesis), system); private law (formal legal, comparative legal). Results: the content of the concept "owner of the source of increased danger" is revealed. The problem of lack of transparency of information about the owner of the vehicle, its causes and consequences is raised. Considered the actual use of digital technologies today in this area and proposed ways to develop the protection of subjects of law from the possibility of illegal actions. Conclusions: the characteristics of the basic concept of "owner of a source of increased danger" are defined, the influence of digital technologies on the institution of a source of increased danger is considered. It is revealed that the identification of the concepts "owner of the source of increased danger" and "owner of the property" can lead to a mixture of proprietary relations and non-contractual obligations, requiring their specific legal regulation. The analysis of the new electronic title is carried out, as well as the further prospects of its development are revealed. The approximate list of data necessary for safety of the subject which enters the legal relationship connected with use by the vehicle is specified.
\end{abstract}

Key words: information technologies, delictual liability, civil responsibility, source of increased danger, owner of the source of increased danger, vehicle, electronic title.

Citation. Deryugina S.R. Transformation of the Institute of the Source of Increased Danger in the Information and Digital Era. Legal Concept, 2019, vol. 18, no. 4, pp. 35-39. (in Russian). DOI: https://doi.org/10.15688/ lc.jvolsu.2019.4.4

\section{ТРАНСФОРМАЦИЯ ИНСТИТУТА ИСТОЧНИКА ПОВЫШЕННОЙ ОПАСНОСТИ КАК СЛЕДСТВИЕ РАЗВИТИЯ ИНФОРМАЦИОННО-ТЕЛЕКОММУНИКАЦИОННЫХ ТЕХНОЛОГИЙ}

\section{Софья Романовна Дерюгина}

\author{
Волгоградский государственный университет, г. Волгоград, Российская Федерация
}

Введение: разработка новейших информационно-телекоммуникационных технологий, применяемых в гражданско-правовой сфере, трансформирует понимание и применение деликтной ответственности за вред, причиненный источником повышенной опасности. Осуществление деятельности, связанной с этим источником предполагает наличие угрозы причинения вреда субъектам права. Для обеспечения наибольшей защиты субъектов применяются цифровые технологии. Выявленные проблемы механизма применения 
цифровых технологий для защиты субъективных прав требуют проведения научного анализа для определения сущностных изменений института источника повышенной опасности. Цель: охарактеризовать понятие «владелец источника повышенной опасности», рассмотреть влияние цифровых технологий на институт источника повышенной опасности. В процессе анализа использовались следующие методы: всеобщий - диалектический и метафизический; общенаучные - логический (индукция, дедукция, анализ, синтез), системный; частноправовые - формально-юридический, сравнительно-правовой. Результаты: раскрыто наполение термина «владелец источника повышенной опасности». Рассмотрена проблема отсутствия прозрачности сведений о владельце транспортного средства, ее причины и следствия. Проанализировано фактическое применение цифровых технологий в сфере отношений, связанных с использованием источника повышенной опасности, и предложены способы развития охраны субъектов права от возможности противоправных действий. Представлен анализ нового электронного паспорта транспортного средства, а также определены дальнейшие перспективы его использования. Выводы: выявлено, что отождествление понятий «владелец источника повышенной опасности» и «владелец имущества» может привести к смешению вещного и обязательственного внедоговорного отношений, требующих своего специфического правового регулирования. Указан примерный перечень данных, необходимых для обеспечения безопасности субъекта, который вступает в правоотношения, связанные с использованием транспортного средства.

Ключевые слова: информационные технологии, деликтная ответственность, гражданско-правовая ответственность, источник повышенной опасности, владелец источника повышенной опасности, транспортное средство, электронный ПТС.

Цитирование. Дерюгина С. Р. Трансформация института источника повышенной опасности как следствие развития информационно-телекоммуникационных технологий // Legal Concept = Правовая парадигма. - 2019. - Т. 18, № 4. - C. 35-39. - DOI: https://doi.org/10.15688/lc.jvolsu.2019.4.4

\section{Введение}

В связи с небывалым темпом развития информационно-телекоммуникационных технологий существенно видоизменяется облик современного общества. Цифровые экономические отношения, привлекая своим удобством, вытесняют привычные нам традиционно-хозяйственные. В научной литературе справедливо отмечается, что имеющиеся теоретические разработки в юридической доктрине уже не отвечают потребностям современного общества [2, с. 7].

В настоящее время в гражданский оборот вводятся новейшие цифровые разработки. Указанная модификация приводит к изменению понимания и применения деликтной ответственности за вред, причиненный источником повышенной опасности. Поэтому изучение данного вопроса и последовательное закрепление в законодательстве нового правового регулирования института источника повышенной опасности является актуальной задачей гражданского права.

Эксплуатация транспортного средства (далее - ТС), выступающая одной из основных составляющих данного института, предполагает наличие непосредственной опасности для субъектов гражданско-правовых отно- шений. В связи с этим причинение вреда источником повышенной опасности выделяют в специальный деликт, который обусловлен отсутствием фактического причинителя вреда и противоправности в его деятельности. Характеристики субъекта правоотношения и его действий не имеют значения для возникновения данного обязательства, необходимо только условие причинения вреда.

\section{Содержание понятия «владелец источника повышенной опасности»}

Отличительная особенность института источника повышенной опасности отражается в содержании понятия «владелец источника повышенной опасности». Владельцем признается лицо: 1) обладающее соответствующим правомочием, а именно - правом собственности, хозяйственного ведения или другим вещным правом; 2) фактически эксплуатирующее данный объект либо иначе осуществляющее за ним контроль. Указанные признаки позволяют пресечь неопределенность в судебной практике и отграничить ответственность владельцев источников повышенной опасности от других лиц, связанных с такими источниками иными материальными правоотношениями. 
Согласно законодательству собственником является лицо, выступающее в роли владельца, пользователя, распорядителя имуществом, у которого есть соответствующие правоустанавливающие документы на имущество. Владелец в свою очередь - лицо, имеющее право на владение, пользование имуществом. Согласно указанному определению владельцу необходимо осуществлять эксплуатацию объекта, и только в этом случае применимы нормы ст. 1079 ГК РФ. Следовательно, отождествление понятий «владелец источника повышенной опасности» и «владелец имущества» может привести к смешению вещного и обязательственного внедоговорного отношений, требующих своего специфического правового регулирования.

Владелец источника повышенной опасности признается титульным владельцем при наличии правоустанавливающих документов, указанных законодательством, является титульным владельцем, что подтверждается наличием правоустанавливающих документов, указанных законодательством. Эксплуатация источника повышенной опасности в качестве владельца такового возможна только на гражданско-правовых основаниях, к чему не относится управление данным источником по трудовому договору. Помимо этого, при определении ответственности владельца неподконтрольного объекта необходимо учитывать в чьих интересах проводилось использование объекта. Вместе с тем осуществление деятельности, создающей повышенную опасность для окружающих без специального разрешения или иных обстоятельств, влияющих на вину владельца, не играет роли при квалификации лица в качестве владельца источника повышенной опасности.

Ответственность за вред, причиненный источником повышенной опасности, наступает только при условии, что данный объект материального мира либо деятельность не могли быть в должной степени проконтролированы человеком и вред был причинен теми опасными свойствами источника, которые обусловливают признание его таковым. Это обстоятельство имеет важное значение для квалификации содеянного и, соответственно, определения общей или повышенной ответственности. Из-за указанной специфики законода- тель устанавливает особую защиту потерпевших от действия источников повышенной опасности посредством закрепления порядка, при котором отсутствие вины не освобождает владельца данного источника от деликтной ответственности.

\section{Цифровые технологии как способ обеспечения безопасности и защиты субъектов права при эксплуатации источника повышенной опасности}

Указом Президента РФ «О Стратегии развития информационного общества в Российской Федерации на 2017-2030 годы» [7, c. 24] устанавливаются основные положения эффективного развития информационного общества в России. Одним из главных принципов настоящей Стратегии является обеспечение безопасности и защиты российских граждан при использовании цифровых технологий. Однако в настоящее время возникают системные проблемы правового регулирования отношений с использованием сети Интернет, в том числе обусловленные отсутствием необходимой информации, обеспечивающей возможность защиты субъективных прав граждан [1, с. 58].

Полагаем, что целесообразно указание в цифровой системе сведений и о ТС, и о его владельце. Например, с 2019 г. в России планируется полностью заменить бумажные паспорта транспортных средств (далее - ПТС) на электронные [6, с. 5]. Представляется необходимым указание в ПТС сведений, содержащих информацию о собственнике ТС, наличии обременительных отношений, касающихся данного объекта (ТС), авариях, ремонте [4, с. 7].

Оформлением электронного паспорта могут заниматься таможенные органы, автопроизводители, органы ГИБДД и др. [6, с. 9]. Следовательно, информация из электронного ПТС предоставляется в наиболее полном объеме только представителям органов государственной власти (отделы ГИБДД, ФНС, ФССП) [5, с. 6]. Однако персональные данные самого владельца могут быть указаны только при его согласии с применением всех положений Ф3 «О персональных данных» [8, 
c. 59]. При этом информация должна быть полностью защищена от искажения субъектами гражданско-правовых отношений. Однако возможная затянутость процесса, потеря исходных данных, зависание и неполадки систем в связи с огромным информационным потоком понижают эффективность внедрения цифровых технологий в эту отрасль. Преодолением таких негативных факторов может послужить замена технологического оборудования современными цифровыми машинами, налаживание процесса функционирования обслуживающей инфраструктуры и правовой базы.

Доступ к данным электронного ПТС получит будущий владелец, который официально переоформляет вещное право на ТС [3, c. 56] (в настоящее время при заключении договора купли-продажи автомобиля покупатель лишен возможности отследить историю $\mathrm{TC}$, следовательно, становится более уязвимым для недобросовестного продавца). Ему будут доступны сведения о фактическом существовании автомобиля, статусе электронного ПТС, наличии обременений на ТС. Однако такую информацию нельзя считать полноценной [6, с. 23]. Наибольшая открытость процесса эксплуатации ТС текущим владельцем приводит к более высокой защищенности третьих лиц, вступающих в договорные отношения с субъектом, владеющим ТС.

\section{Выводы}

Стремительный переход индустриального общества в информационное с объективной необходимостью влечет совершенствование методов правового регулирования данной сферы отношений. Возможность полного возмещения вреда, причиненного гражданским правонарушением, повлекшим возникновение деликтного обязательства, является гарантией гармоничного развития социума на пути формирования правового государства. Трансформация института источника повышенной опасности происходит посредством внедрения информационно-телекоммуникационных технологий. Информационные технологии, являющиеся неотъемлемой частью жизни потребителей нашего времени, не только предоставляют людям новые возможности, но и спо- собствуют повышению уровня защиты прав граждан. Следовательно, введение электронных ПТС позволит повысить уровень защищенности субъектов, вступающих в гражданско-правовые отношения с владельцем ТС. При этом необходимо законодательно установить ограничения для получения и использования данной информации в зависимости от того, в какие гражданско-правовые отношения вступают стороны.

\section{СПИСОК ЛИТЕРАТУРЫ}

1. Иншакова, А. О. Системные проблемы правового регулирования деятельности информационных агрегаторов / А. О. Иншакова, М. В. Севастьянов, Т. В. Дерюгина // Ubiquitous Computingand the Internet of Things: Prerequisites for the Development of ICT / ed. by E. G. Popkova. - [Б. м.] : Springer, 2019. - P. 58-64. - (Studies in Computational Intelligence).

2. Иншакова, А. О. Юридическая ответственность из деликтных обязательств: межотраслевые интерпретации современной юридической мысли // Legal Concept = Правовая парадигма. -2018 . T. 17, № 1. -C. 4-12. - DOI: https://doi.org/10.15688/ lc.jvolsu.2018.1.1.

3. Касенова, М. Б. Идентификация лиц в Интернете и киберпространство социальных сетей / М. Б. Касенова // Юрист. - 2014. - № 6. - С. 56-60.

4. Постановление Правительства Российской Федерации от 12.08.1994 № 938 «О государственной регистрации автомототранспортных средств и других видов самоходной техники на территории Российской Федерации» // Собрание законодательства Российской Федерации. - 1994. - 22 авг. (№ 17). - 276 с.

5. Постановление Правительства Российской Федерации от 05.10.2017 № 1212 «О некоторых вопpocax, связанных с введением в Российской Федерации электронного паспорта транспортного средства и электронного паспорта шасси транспортного средства» // Российская газета. - 2017. 18 окт. (№ 235.). -75 c.

6. Решение Коллегии Евразийской экономической комиссии от 22.09.2015 № 122 «Об утверждении Порядка функционирования систем электронных паспортов транспортных средств (электронных паспортов шасси транспортных средств) и электронных паспортов самоходных машин и других видов техники» // Евразийский экономический союз. - Электрон. текстовые дан. - Режим доступа: http://www.eaeunion.org. - Загл. с экрана.

7. Указ Президента Российской Федерации от 09.05.2017 № 203 «О Стратегии развития информа- 
ционного общества в Российской Федерации на 2017-2030 годы» // Официальный интернет-портал правовой информации. - Электрон. текстовые дан. - Режим доступа: http://www.pravo.gov.ru. Загл. с экрана.

8. Федеральный закон от 27.07.2006 № 152-Ф3 (ред. от 31.12.2017) «О персональных данных» // Собрание законодательства Российской Федерации. 2006. - 31 июля (№ 31). -543 с.

\section{REFERENCES}

1. Inshakova A.O., Sevastyanov M.V., Deryugina T.V. Sistemnye problemy pravovogo regulirovaniya deyatelnosti informatsionnykh agregatorov [Systemic Problems of Legal Regulation of Information Aggregators]. Popkova E.G. ed. Ubiquitous Computing and the Internet of Things: Prerequisites for the Development of ICT. Springer, 2019, pp. 58-64. (Studies in Computational Intelligence).

2. Inshakova A.O. Yuridicheskaya otvetstvennost iz deliktnykh obyazatelstv: mezhotraslevye interpretatsii sovremennoy yuridicheskoy mysli [Legal Lability of Tort Obligations: Interdisciplinary Interpretations of Modern Legal Thought]. Legal Concept = Pravovaya paradigma, 2018, vol. 17, no. 1, pp. 4-12. DOI: https:// doi.org/10.15688/lc.jvolsu.2018.1.1.

3. Kasenova M.B. Identifikatsiya lits v Internete i kiberprostranstvo sotsialnykh setey [Identification of Persons in Internet and Cyberspace of Social Networks]. Yurist [Jurist], 2014, no. 6, pp. 56-60.

4. Postanovlenie Pravitelstva Rossiyskoy Federatsii ot 12.08.1994 № 938 «O gosudarstvennoy registratsii avtomototransportnykh sredstv i drugikh vidov samokhodnoy tekhniki na territorii Rossiiskoy Federatsii» [Genesovlenie of the Government of the Russian Federation of 12.08.1994 no. 938 “ About the State Register of Motor Vehicles and Other Types of Self-Propelled Equipment in the Territory of Russia of Federation"]. Sobranie zakonodatelstva Rossiyskoy
Federatsii [Collection of Legislative Acts of the Russian Federation], 1994, August 22, no. 17. 276 p.

5. Postanovlenie Pravitelstva Rossiyskoy Federatsii ot 05.10.2017 № 1212 «O nekotorykh voprosakh, svyazannykh s vvedeniem v Rossiyskoy Federatsii elektronnogo pasporta transportnogo sredstva i elektronnogo pasporta shassi transportnogo sredstva» [Genesovlenie Pravitelstvo RF ot 05.10.2017 N 1212 "About Some Questions Connected with Introduction in the Russian Federation of the Electronic Passport Vehicles and Electronic Passports of the Chassis Vehicles"]. Rossiyskaya gazeta [Russian Newspaper], 2017, October 18, no. 235. 75 p.

6. Reshenie Kollegii Evraziyskoy ekonomicheskoy komissii ot 22.09.2015 № 122 «Ob utverzhdenii Poryadka funktsionirovaniya sistem elektronnykh pasportov transportnykh sredstv (elektronnykh pasportov shassi transportnykh sredstv) i elektronnykh pasportov samokhodnykh mashin i drugikh vidov tekhniki» [Decision of Board of the Eurasian Economic Commission of 22.09.2015 No. 122 “About the Statement of the Order of Functioning of Systems of Electronic Passports of Vehicles (Electronic Passports of the Chassis of Vehicles) and Electronic Passports of SelfPropelled Cars and Other Types of Equipment"]. Evraziyskiy ekonomicheskiy soyuz [Eurazian Economic Union]. URL: http://www.eaeunion.org.

7. Ukaz Prezidenta Rossiyskoy Federatsii ot 09.05.2017 № 203 «O Strategii razvitiya informatsionnogo obshchestva $\mathrm{v}$ Rossiyskoy Federatsii na 2017-2030 gody» [The Decree of the President of the Russian Federation of May 09, 2017 No. 203 "About Strategy of Development of Information Society in the Russian Federation for 2017-2030"].Ofitsialnyy Internetportal pravovoy informatsii [Official Internrt-Portal of Legal Information]. URL: http://www.pravo.gov.ru.

8. Federalnyyzakon ot 27.07.2006 № 152-FZ(red. ot 31.12.2017) «O personalnykh dannykh» [Federal Law of 27.07.2006 No. 152-FZ (As Amended on 31.12.2017) "On Personal Data"]. Sobranie zakonodatelstva Rossiyskoy Federatsii [Collection Legislation of the Russian Federation], 2006, Jule 31, no. 31. 543 p.

\section{Information about the Author}

Sophia R. Deryugina, Master Student, Department of Civil and International Private Law, Volgograd State University, Prosp. Universitetsky, 100, 400062 Volgograd, Russian Federation, sofiaderugina3764@mail.ru, https://orcid.org/0000-0002-3650-8821

\section{Информация об авторе}

Софья Романовна Дерюгина, магистрант кафедры гражданского и международного частного права, Волгоградский государственный университет, просп. Университетский, 100, 400062 г. Волгоград, Российская Федерация, sofiaderugina3764@mail.ru, https://orcid.org/0000-0002-3650-8821 